\title{
Modeling and simulation: the paradigm shift for cohesive resource harnessing
}

\begin{abstract}
This paper presents the details of a specialized framework developed for the teaching of the modeling and simulation course for postgraduate students in Universiti Putra Malaysia. The unique feature of the subject is that it requires students ability to gain knowledge in several fields and relate them aptly to the need of performance analysis. IT also demands acquiring skills to develop comprehensive tools using the principles of discrete event simulation. The developed framework focuses on student-centered learning of queuing analysis, the development of models and relating them to performance analysis, the specialized activities to derive discrete event simulation components, and output analysis. It also deals with the tool's impact on research within the area. The framework was evaluated in a course. It showed the ability to enhance the level of student's understanding and application of competency gained to research.
\end{abstract}

Keyword: Discrete-event; Performance analysis; Simulation 